\title{
Randomized controlled trial of single incision versus conventional multiport laparoscopic cholecystectomy with long-term follow-up
}

\author{
Denis Klein ${ }^{1} \cdot$ Atakan Görkem Barutcu ${ }^{1} \cdot$ Dino Kröll $^{1} \cdot$ Maik Kilian $^{1,2} \cdot$ Johann Pratschke $^{1} \cdot$ Roland Raakow $^{3}$. \\ Jonas Raakow ${ }^{1}$ (D)
}

Received: 2 April 2020 / Accepted: 12 June 2020 / Published online: 29 June 2020

(C) The Author(s) 2020

\begin{abstract}
Background Within the last years, single-incision laparoscopic cholecystectomy (SLC) emerged as an alternative to multiport laparoscopic cholecystectomy (MLC). SLC has advantages in cosmetic results, and postoperative pain seems lower. Overall complications are comparable between SLC and MLC. However, long-term results of randomized trials are lacking, notably to answer questions about incisional hernia rates, long-term cosmetic impact and chronic pain.

Methods A randomized trial of SLC versus MLC with a total of 193 patients between December 2009 and June 2011 was performed. The primary endpoint was postoperative pain on the first day after surgery. Secondary endpoints were conversion rate, operative time, intraoperative and postoperative morbidity, technical feasibility and hospital stay. A long-term follow-up after surgery was added.

Results Ninety-eight patients (50.8\%) underwent SLC, and 95 patients (49.2\%) had MLC. Pain on the first postoperative day showed no difference between the operative procedures (SLC vs. MLC, $3.4 \pm 1.8$ vs. $3.7 \pm 1.9$, respectively; $p=0.317$ ). No significant differences were observed in operating time or the overall rate of postoperative complications $(4.1 \%$ vs. $3.2 \% ; p=$ 0.731). SLC exhibited better cosmetic results in the short term. In the long term, after a mean of 70.4 months, there were no differences in incisional hernia rate, cosmetic results or pain at the incision between the two groups.

Conclusions Taking into account a follow-up rate of $68 \%$, the early postoperative advantages of SLC in relation to cosmetic appearance and pain did not persist in the long term. In the present trial, there was no difference in incisional hernia rates between SLC and MLC, but the sample size is too small for a final conclusion regarding hernia rates.

Trial registration German Registry of Clinical Trials DRKS00012447
\end{abstract}

Keywords Laparoscopic surgery $\cdot$ Single-incision $\cdot$ Single-port $\cdot$ Cholecystectomy $\cdot$ Multiport

\section{Introduction}

Since the first laparoscopic cholecystectomy was performed by Mühe et al. in 1985, significant progress in the practice of

Jonas Raakow

jonas.raakow@charite.de

1 Department of Surgery, Charité Campus Mitte, Campus Virchow Klinikum, Charité - Universitätsmedizin Berlin, corporate member of Freie Universität Berlin, Humboldt-Universität zu Berlin, and Berlin Institute of Health, Charitéplatz 1, 10117 Berlin, Germany

2 Department of General and Visceral Surgery, Evangelische Elisabeth Klinik, Lützowstraße 26, 10785 Berlin, Germany

3 Department of General, Visceral and Vascular Surgery, Vivantes Klinikum Am Urban, Dieffenbachstrasse 1, 10967 Berlin, Germany minimal invasive gallbladder surgery revolutionized the surgical treatment of benign gallbladder diseases [1]. Conventional multiport laparoscopic cholecystectomy (MLC) is the gold standard, but new techniques were introduced to further minimize the impact of surgery. One-wound laparoscopy, later described as single-incision or single-port laparoscopic surgery (SLS), was first introduced by Navarra et al. in 1997 [2]. Within the last few years, this surgical procedure received increasing attention, and several authors documented the safety and feasibility of SLS in a wide variety of surgical indications [3-6]. SLS has a positive cosmetic effect because of a single transumbilical incision, and it produces less pain and faster recovery due to the reduction of incisional trauma [7-10]. Single-incision laparoscopic cholecystectomy (SLC) is becoming more established as a potential new standard surgery for gallbladder diseases, and numerous 
reports were published for elective cholecystectomy. Singleincision surgery produces similar results as conventional multiport laparoscopic cholecystectomy, particularly conversion and complication rates. However, long-term results, especially umbilical incisional hernia rates, are lacking and subject to controversy [11-14].

Therefore, we performed a randomized trial to compare single-port with multiport laparoscopic cholecystectomy within the early days of single-port laparoscopy and added a longterm follow-up of the patients with particular focus on the development of incisional hernias and long-term cosmetic results.

\section{Methods}

The study was designed as a prospective randomized clinical trial at a single institution between December 2009 and June 2011. Approval was obtained from the local ethics committee and the institutional review board. The study is registered at the German Registry of Clinical Trials (registration number DRKS00012447). All subjects provided written informed consent prior to inclusion in the study.

The following inclusion criteria were used: age over 18 years and indication for laparoscopic cholecystectomy (symptomatic cholecystolithiasis, cholecystitis or gallbladder polyps). Exclusion criteria included contraindications to laparoscopy, American Society of Anesthesiologists (ASA) class IV or $\mathrm{V}$, pregnancy or lactation.

\section{Randomization and outcome measurement}

All patients were randomized at a 1:1 ratio to SLC or MLC procedure via the drawing of sealed opaque envelopes containing computer-generated random numbers before the start of surgery. A third party prepared the envelopes, and block sizes of two and four were used randomly and unknown to the operating surgeon.

The primary outcome was the measurement of pain on the first postoperative day using a visual analogue scale (VAS). Pain scores were recorded on the morning of the first postoperative day and the day of discharge.

Secondary endpoints were conversion rate, operative time, intraoperative and postoperative morbidity, technical feasibility and hospital stay. The operative time was defined as the time from the skin incision to the complete application of all wound dressings. Intraoperative complications were defined as any adverse event during the surgery that required additional intervention or treatment. Postoperative morbidity was defined as any adverse event that required additional medical or surgical intervention during the short-term follow-up and was classified according to Dindo et al. [15]. The length of hospital stay was the time from admission to discharge, counting the day of admission and operation as day 0 . The surgeon who performed the operation documented the technical feasibility immediately after skin closure on a 10-point scale where 1 represented very good feasibility and 10 represented the worst surgical feasibility.

After an initial analysis, we added a long-term follow-up of all patients. Therefore, we added the rate of incisional hernia and cosmetic result of the long-term follow-up to the secondary endpoints.

\section{Surgical procedures}

The surgical techniques for MLC and SLC were standardized. Three experienced laparoscopic surgeons, each of whom performed over $100 \mathrm{ML}$ and more than $50 \mathrm{SIL}$ cholecystectomies, performed or supervized all surgeries. Prophylactic antibiotic therapy in both groups consisted of single-shot cefotaxime $(2 \mathrm{~g})$ and metronidazole $(500 \mathrm{mg})$, which were administered intravenously shortly before the skin incision. Patients for MLC and SLC were placed in a supine position with both surgeons standing on the left side of the patient.

Access to the abdominal cavity for SLC procedures was achieved via mini-laparotomy through a single transumbilical 15- to 20-mm skin and fascial incision. A commercial port system (TriPort ${ }^{\mathrm{TM}}$ or TriPort $\mathrm{t}^{\mathrm{TM}}$; Olympus, Japan) was inserted with the aid of the supplied introducer. A $30^{\circ} 5$ - or 10-mm laparoscope and two standard straight $5-\mathrm{mm}$ working instruments were inserted through the port system.

The MLC was a three-port approach, and the pneumoperitoneum was established using a Veress needle. A 10-mm trocar was placed subumbilically for the $30^{\circ}$ laparoscope, and two working trocars $(5$ and $10 \mathrm{~mm}$ ) were inserted under sight epigastrically and in the middle right lateral region.

Calot's triangle was dissected in all procedures, and the cystic duct and artery were ligated using a 5-mm endoscopic clip applier (Ligamax $5 \mathrm{M} / \mathrm{L}$, Ethicon, USA) and divided with scissors. The gallbladder was carefully dissected from the fossa. The gallbladder was removed directly through the port system in SLC procedures, which also acts as a wound protector. Gallbladder extraction for MLC was done via the umbilical incision with a retrieval bag to avoid wound contamination. The umbilical and $10-\mathrm{mm}$ incisions were closed using non-absorbable 0 sutures for the fascial incision and absorbable 4-0 monofilament sutures for skin closure. We did not apply local anaesthetics around the trocar incisions as pain medication.

\section{Postoperative care and follow-up}

All patients received the same standard analgesia prescription during the postoperative care. This care consisted of $1000 \mathrm{mg}$ metamizole intravenously three times daily for the first postoperative day and was reduced to $500 \mathrm{mg}$ metamizole orally 
three times daily until discharge. A rescue medication of $50 \mathrm{mg}$ tramadol orally was titrated up to three times daily on demand until the VAS pain score was lower than 3. Patients were discharged around the second day after surgery as soon as oral feeding was tolerated, and there were no signs of fever or uncontrolled pain.

The follow-up was started in August 2016 via letter correspondence with the patients. The questionnaire included information on clinical symptoms that suggest incisional hernia, information on any other abdominal surgery after the cholecystectomy and questions about the patient's cosmetic opinion of the scar and pain or discomfort at the scar. If no response was received by the end of 2016, patients were contacted by telephone up to three times with at least 1 week in between contact attempts. If no response was achieved, patients were counted as lost to follow-up due to no contact. All patients were asked the same questions to detect an incisional hernia according to the findings of Baucom et al. [16]. In cases of further abdominal surgery after the cholecystectomy, more information about the diagnosis and the extent of the surgery was obtained to exclude any manipulation at the access sites of the cholecystectomy. Contacted patients, especially patients with inconclusive results after the letter and/or telephone contact, were invited for a clinical examination. Clinical examination consisted of palpatory evaluation at rest and under strain and dynamic ultrasound imaging of the laparoscopic access sites. Patients who were converted to an open surgery during SLC or MLC were excluded from the follow-up. The time of letter response, telephone or clinical contact was marked as the follow-up date. The latest date was recorded in cases of multiple contacts. Patients who underwent a further abdominal surgery after the cholecystectomy had their followup date recorded as the date of that particular surgery. Patient's overall opinion of the scar was also measured on a scale ranging from 1 to 10 where patients were asked to rate their scar between "like normal skin" (1) and "very different" (10).

\section{Statistical analysis}

All patient data, including clinical history, demographic factors, laboratory data, indication and details of the surgical procedure, intraoperative findings and postoperative short- and long-term outcomes, were prospectively recorded in a specific database.

The hypothesis was that SLC was associated with less postoperative pain compared with MLC as measured using a VAS score. The sample size calculation was performed before the study was initiated. To identify a difference of 1 point in VAS score with an estimated standard deviation of 2 , it was calculated that 84 patients were required per group with a power of $90 \%$ and a type 1 error of $5 \%$. With the assumption of at least $10 \%$ patient loss to follow-up or dropout in each group, a total sample size of approximately 190 patients was planned for inclusion.
All analyses were based on the intention-to-treat principle, and losses were not replaced. Variables are described as numbers with percentages as appropriate or as means \pm standard deviation. Categorical variables were compared using the chisquared test $\left(\chi^{2}\right)$. Numerical continuous variables were compared using the Mann-Whitney $U$ test. A $p$ value $<0.05$ was considered statistically significant. All analyses were performed using SPSS (Statistical Product and Service Solutions) version 23 (IBM, USA).

\section{Results}

A total of 193 patients (female $66.8 \%, n=129$ ), aged 19 to 89 years (mean 47.1 years \pm 15.4 years), were randomly assigned to SLC $(n=98)$ or MLC $(n=95)$ (Fig. 1). As shown in Table 1, there was no statistical significance between the two groups in demographic factors, such as age, gender, weight, score of the ASA or previous abdominal surgeries.

Operative times were comparable between groups (Table 2). Intraoperative complications occurred in two patients. Bleeding occurred in one patient undergoing SLC, and a common bile duct injury was found in a patient during MLC, which was treated via suturing and insertion of a T-tube. Two patients in the SLC group needed an additional 5-mm trocar in the epigastrium for better exposure of the hepatoduodenal ligament. No patient in this group was converted to open cholecystectomy. Two patients planned for an MLC were converted to an open procedure due to extensive adhesions.

Surgeons found the single-incision access to be slightly more difficult to perform than the multiport access, but this difference was not statistically significant. The feasibility of the preparation of the gallbladder hilus and fossa was scored similarly in the two groups (Table 3).

Postoperative complications occurred in four patients after SLC and in three patients after MLC ( $4.1 \%$ vs. $3.2 \%$, respectively; $p=0.731)$. A haematoma/seroma in the gallbladder fossa was found in two patients, two patients showed an umbilical haematoma, and one patient developed pneumonia. All of these postoperative complications were grade I or II (Clavien-Dindo). One patient reported prolonged epigastric pain and vomiting, and this patient underwent a gastroscopy without a diagnosis. However, the symptoms improved the day after the intervention. Another patient showed postoperative cholestasis with an endoscopic retrograde cholangiopancreatography that showed swelling of the ductus choledochus, and a papillotomy was performed. These two complications were classified as grade IIIa (Clavien-Dindo).

According to the VAS, pain was similar between the two groups on the morning of the first postoperative day (Table 2), but it was significantly better after SLC on the day of discharge $(1.5 \pm 1.3$ vs. $2.1 \pm 1.5 ; p=0.021)$. The postoperative hospital stay was significantly shorter after SLC than after 
Fig. 1 Consort flow diagram

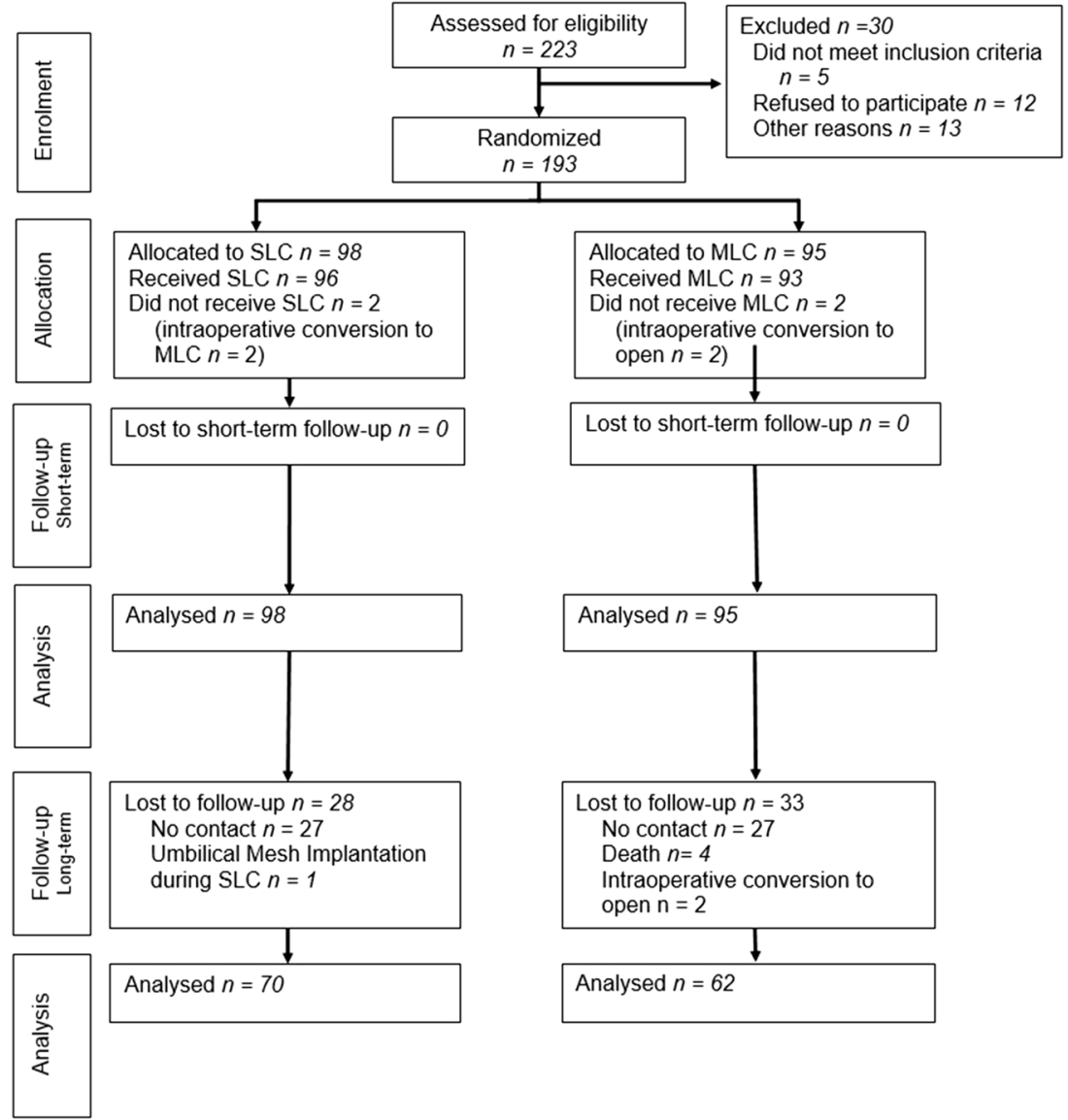

MLC $(3.1 \pm 1.2$ days vs. $4.2 \pm 2.4$ days, respectively; $p<0.001)$.

A total of $68.4 \%$ of all patients completed the follow-up after a mean time of 70.4 months. The shortest follow-up was noted after 3 months, and the longest follow-up was 90 months after the operation. Reasons for loss to follow-up are given in Table 4. The overall rate for incisional hernias was $6.8 \%$ (9/132), with no difference between SLC and MLC (5.7\% vs. $8.1 \%$, respectively; $p=0.593)$. The incisional hernia rates in an intention-to-treat analysis were 5.6\% (4/71) after SLC

Table 1 Demographic parameters

\begin{tabular}{lll}
\hline & SLC $(n=98,50.8 \%)$ & MLC $(n=95,49.2 \%)$ \\
\hline Gender & & $p$ value \\
Male & $27(27.6 \%)$ & $37(38.9 \%)$ \\
Female & $71(72.4 \%)$ & $58(61.1 \%)$ \\
Age (years) & $45.7 \pm 14.9$ & $48.7 \pm 15.8$ \\
BMI $\left(\mathrm{kg} / \mathrm{m}^{2}\right)$ & $28.4 \pm 6.0$ & $28.8 \pm 6.2$ \\
ASA score & & \\
I & $50(51.0 \%)$ & $34(36.2 \%)$ \\
II & $42(42.9 \%)$ & $49(52.1 \%)$ \\
III & $6(6.1 \%)$ & $11(11.7 \%)$ \\
Previous abdominal surgery & $23(23.5 \%)$ & $30(31.6 \%)$ \\
Diagnosis & & \\
Chronic cholecystitis and others & $87(88.8 \%)$ & $79(83.2 \%)$ \\
Acute cholecystitis & $11(11.2 \%)$ & $16(16.8 \%)$ \\
\hline
\end{tabular}

Values are presented as numbers and percentage or in means \pm standard deviation

$B M I$ body mass index, ASA American Society of Anesthesiologists 
Table 2 Operative details

\begin{tabular}{|c|c|c|c|}
\hline & $\begin{array}{l}\text { SLC } \\
(n=98,50.8 \%)\end{array}$ & $\begin{array}{l}\text { MLC } \\
(n=95,49.2 \%)\end{array}$ & $p$ value \\
\hline Operative time (minutes) & $55.6 \pm 18.3$ & $57.0 \pm 17.4$ & 0.430 \\
\hline Peritoneal adhesions & $33(33.7 \%)$ & $45(47.4 \%)$ & 0.058 \\
\hline Gallbladder perforation & $17(17.3 \%)$ & $24(25.3 \%)$ & 0.179 \\
\hline Intraoperative complication & $1(1.0 \%)$ & $1(1.1 \%)$ & 0.368 \\
\hline Conversion & & & 0.975 \\
\hline $\begin{array}{l}\text { Multiport } \\
\text { Open }\end{array}$ & $\begin{array}{l}2(2.0 \%) \\
-\end{array}$ & $\begin{array}{l}- \\
2(2.1 \%)\end{array}$ & \\
\hline Postoperative complications & $4(4.1 \%)$ & $3(3.2 \%)$ & 0.731 \\
\hline Haematoma/seroma gallbladder fossa & $2(2.0 \%)$ & & \\
\hline Haematoma umbilical port & $1(1.0 \%)$ & $1(1.1 \%)$ & \\
\hline Epigastric pain/vomiting & & $1(1.1 \%)$ & \\
\hline Pneumonia & $1(1.0 \%)$ & & \\
\hline Cholestasis & & $1(1.1 \%)$ & \\
\hline Clavien-Dindo & & & 0.143 \\
\hline $\begin{array}{l}<3 \\
\geq 3\end{array}$ & $\begin{array}{l}4(4.1 \%) \\
-\end{array}$ & $\begin{array}{l}1(1.1 \%) \\
2(2.1 \%)\end{array}$ & \\
\hline Pain at postoperative day 1 (VAS) & $3.4 \pm 1.8$ & $3.7 \pm 1.9$ & 0.317 \\
\hline Pain at discharge (VAS) & $1.5 \pm 1.3$ & $2.1 \pm 1.5$ & 0.021 \\
\hline Hospital stay (days) & $3.1 \pm 1.2$ & $4.2 \pm 2.4$ & $<0.001$ \\
\hline \multicolumn{4}{|l|}{ Histological findings } \\
\hline Chronic inflammation & $79(80.6 \%)$ & $75(78.9 \%)$ & 0.151 \\
\hline Acute inflammation & $8(8.2 \%)$ & $14(14.7 \%)$ & 0.773 \\
\hline Gallstones & $75(76.5 \%)$ & $74(77.9 \%)$ & 0.821 \\
\hline
\end{tabular}

Values are presented as numbers and percentage or in means \pm standard deviation

VAS visual analogue scale

and $7.8 \%(5 / 64)$ following MLC $(p=0.735)$. All hernias in both groups were found at the umbilical incision.

\section{Discussion}

After laparoscopic cholecystectomy had found its way into daily surgical practice, an even further minimization of surgical trauma was achieved using single-incision laparoscopy. The single incision in the navel enables a concealing of the surgical scar by taking advantage of the navel's natural scar. However, the technique is controversial. Several studies demonstrated the safety and feasibility advantages of singleincision cholecystectomy and highlighted other benefits of this technique [8, 17-20]. However, other studies suggested a higher complication rate and, in particular, an increased incidence of incisional hernias [7, 9, 11]. Most of these studies suffered from the disadvantage of short follow-up observation periods. The present study fills this gap with mean follow-up durations of 71.1 months in the SLC and 69.6 months in the MLC group.

The duration of the surgery is a key parameter for comparing surgical methods. No statistically significant differences were observable in this study. While several earlier studies

Table 3 Surgical feasibility

\begin{tabular}{llll}
\hline & SLC $(n=98,50.8 \%)$ & MLC $(n=95,49.2 \%)$ & $p$ value \\
\hline Access & $1.4 \pm 0.6$ & $1.1 \pm 0.3$ & 0.078 \\
Preparation gallbladder hilus & $1.9 \pm 0.8$ & $1.8 \pm 0.7$ & 0.758 \\
Preparation gallbladder fossa & $1.7 \pm 0.7$ & $1.7 \pm 0.8$ & 0.871 \\
\hline
\end{tabular}

Values are presented as numbers and percentage or in means \pm standard deviation 
Table 4 Follow-up

\begin{tabular}{|c|c|c|c|}
\hline & $\operatorname{SLC}(n=98,50.8 \%)$ & $\operatorname{MLC}(n=95,49.2 \%)$ & $p$ value \\
\hline Follow-up available & $70(71.4 \%)$ & $62(65.3 \%)$ & 0.439 \\
\hline Follow-up time (months) & $71.1 \pm 16.1$ & $69.6 \pm 16.6$ & 0.539 \\
\hline \multicolumn{4}{|l|}{ Reasons for loss to follow-up } \\
\hline No contact & $27(27.6 \%)$ & $27(28.4 \%)$ & \\
\hline Death & - & $4(4.2 \%)$ & \\
\hline Umbilical mesh implantation at cholecystectomy & $1(1.0 \%)$ & - & \\
\hline Conversion to open cholecystectomy & - & $2(2.1 \%)$ & \\
\hline Incisional hernia & $4(5.7 \%)$ & $5(8.1 \%)$ & 0.593 \\
\hline Incisional hernia repair & $4(5.7 \%)$ & $4(7.3 \%)$ & \\
\hline Open mesh implantation & 2 & 4 & \\
\hline Laparoscopic IPOM & 2 & - & \\
\hline Overall cosmetic opinion of the scar & $1.5 \pm 0.7$ & $1.7 \pm 1.8$ & 0.401 \\
\hline Pain at the scar & $1.5 \pm 0.8$ & $1.2 \pm 0.8$ & 0.141 \\
\hline
\end{tabular}

Values are presented as numbers and percentage or in means \pm standard deviation

IPOM intraperitoneal onlay mesh)

support this result [8, 20-22], most authors indicate a longer surgery duration [17-19, 23-25] in SLC cases. Several metaanalyses support a longer operative duration [7, 9, 26]. However, all of these meta-analyses reported significant heterogeneity between the observed studies and potential bias effects of a variety of different factors on the time required for surgical completion. Among these factors are the physical condition of the patients, the type of device used in the surgery and the experience of the surgeon. Omar et al. observed a significantly lower duration of the surgery for MLC in a retrospective RCT but also noticed variance in surgery duration during the study period. The first ten SLCs in his study had a duration of 103 min whereas the last ten cases showed a similar duration to the MLC group of $47 \mathrm{~min}$ [19]. Other studies also found a decreasing duration of surgeries with an increasing experience of surgeons $[23,27]$. This result suggests that the duration of the surgery highly depends on the learning curve of the respective surgeon. This may explain the lack of reported difference between SLC and MLC patients in the present study because the participating surgeons were highly experienced and performed more than 50 SLC procedures each. This hypothesis is supported by the study results of laparoscopic cholecystectomy. After its introduction, Zucker et al. described a medium surgery duration of $118 \mathrm{~min}$, which was reduced steadily thereafter [28, 29]. Therefore, the length of SLC surgeries approximates the duration of MLC surgeries with increasing experience.

The conversion rate within both groups was similar, which supports the results in the relevant literature [10]. In contrast, Haueter and colleagues and Evers et al. found a significantly higher necessity of additional trocars in the SLC group, but the conversion rate to open cholecystectomy was similar in both groups [9, 26]. Omar et al. defined success as surgeries that were completed without additional trocars or conversion to open cholecystectomy. He referred to significantly higher success rates in the MLC group and a higher necessity for conversion in the SLC group. If the first ten cases are set aside, then the conversion rates in both groups were adjusted [19].

The prolonged duration of surgery and the higher conversion rate suggests that some technical difficulties are associated with the SLC technique. Several studies examined the question of difficulty of the SLC technique and concluded that SLC produced more discomfort [18] and involved a more challenging handling of the instruments [24] and a higher level of exposition of the gallbladder [30], physical exertion and stress [31]. The preparation of the gallbladder was reported as equally difficult [24, 30], but the removal was easier in the SLC group compared with the MLC group [24]. Some disadvantages in the handling of the instruments due to the lack of triangulation were stated [17, 23, 25, 32, 33]. Surgeons in the present trial evaluated the difficulties of the surgical access, the preparation of the gallbladder hilus and the preparation of the gallbladder fossa. No differences in these difficulties were found between the surgical techniques. Notably, the occurrence of a learning curve is mentioned in the literature, but only experienced surgeons participated in the present study. Analogous to the duration of surgery, the conversion rates exhibit comparable feasibility with increasing experience of the surgeons [27].

The present study found no significant differences in the occurrence of intraoperative complications. Bile duct injuries are a rare but particularly feared complication in gallbladder surgery that highly impact postoperative morbidity [34, 35]. An increased incidence of bile duct injuries was not supported 
in the present study, but it was reported by some authors [36, 37]. Recent studies presented comparable results of a similar occurrence of bile duct injuries using both surgical techniques $[9,10,17,19,21,38]$. Arezzo et al. examined the occurrence of complications in a recently published meta-analysis and observed a higher complication rate of severe complications (Cavien-Dindo $\geq 3$ ) in the SLC group, which is similar to that in Evers et al. and Saad et al. [7, 24, 26]. However, there was no difference in bile duct injuries. However, a larger patient collective than that in the present study or meta-analysis is required to make a reliable statement of the real rate of rare complications, such as bile duct injuries.

SLC patients in the present study had a significantly shorter hospital stay compared to MLC patients. Recent studies only partially support these results and showed a lower $[10,25]$ or equivalent $[7,9,17-20]$ length of hospital stay for patients in the SLC group. Even though the results from the present study with 3 to 4 days of hospital stay appear long at first sight, it represents our daily routine because elderly or critically ill patients as well as patients with acute inflammation or previous abdominal surgery were not excluded in this study and might therefore prolong the mean hospital stay. However, the length of hospital stay depends on a variety of factors, such as the occurrence of complications, pain intensity and hospital policies. Therefore, comparisons of the duration of hospital stays across geographical and cultural regions and health systems are highly questionable. For more than a decade, a discussion is ongoing whether laparoscopic cholecystectomies can be performed as day-surgery surgeries. An updated review of the Cochrane Database and a recent meta-analysis conclude that it appears to be as safe as overnight laparoscopic cholecystectomy in selected patients, but the overall effectiveness for the patient is still unclear $[39,40]$. Besides the guidelines by the Society of American Gastrointestinal and Endoscopic Surgeons (SAGES), also, an Italian working group recently stated in their consensus conference guidelines that elective day-surgery laparoscopic cholecystectomy can be considered in carefully selected patients [41, 42].

Regarding the primary endpoint of the present study, we found a tendency of less pain on the morning of the first postoperative day in the SLC group, but without statistical significance. The VAS pain score on the day of the patients' discharge from the hospital was significantly in favour of SLC. Postoperative pain in the literature is controversial. A significant limitation in the comparability of techniques is the use of different follow-up periods and considerable heterogeneity in results and methodologies between the individual studies. Overall, the measurement of postoperative pain in the relevant literature was not standardized, and it was performed at different times. Although the benefits of SLC are not supported consistently in the literature, a trend towards lower pain levels after SLC was observed. Arezzo et al. showed significantly lower pain intensity in the SLC group, but the results in the individual studies analysed were measured at eight different time points [7]. Haueter and colleges demonstrated significantly lower pain intensity in the first $12 \mathrm{~h}$ after SLC surgery, but statistical significance diminished at all other observed time points of pain follow-up. After 7 days, a trend of higher pain levels in the SLC group was reported [9]. Tamini et al. showed significant advantages in postoperative pain intensity in favour of the SLC technique after $24 \mathrm{~h}$, which is supported by our results [10]. Further randomized studies confirmed the improved pain relief after SLC compared with MLC [8, 18, 20, 43], but others showed no difference $[17,19,21]$. Some studies suggested more postoperative pain $[22,23,38]$. The hypothesis was that pain would result in an enlarged fascial incision at the navel, which is the most painful incision in the process [44]. Removal of the first ten surgical observations from Deveci et al. revealed a significant difference [23]. These results suggest that the pain reduction was due to improved surgical experience, and a decrease in operative trauma resulting from a lower mechanical force and strain of the tissue [45]. Very few data are available on chronic pain following SLC in comparison with MLC. Christoffersen et al. did not find a difference in chronic pain [14], which is consistent with our results.

Another factor in patient's postsurgical satisfaction is their general contentment with the cosmetic result of the surgery. The relevant literature illustrates consistency in this regard and shows the benefits of the SLC technique [7, 8, 10, 17, 18, 20, $22,23,26]$. However, most studies included results only up to 12 months postoperatively. The present study found no difference between SLC and MLC in the cosmetic results approximately 6 years after surgery. These findings are consistent with the long-term cosmetic results. Bencsath et al. claimed that the cosmetic benefits were overrated and showed that patients forgot the number of trocars that were used after 21 months [44].

The cost-effectiveness of SLC is still a subject of ongoing debate. Two randomized trails report results regarding the cost of the operation. Bucher et al. found the cost of SLC to be higher in a Swiss trial, and Pan et al. from China report equivalent operative costs compared to MLC $[8,20]$. In retrospective studies, the results differ from lower to substantially higher cost for SLC [46-49]. One of the main cost factors in SLC is the use of a disposable commercial port system which can be significantly reduced by the usage of a reusable port as reported by Shussmann et al. [49].

The widespread view is that the greater length of the naval incision in the SLC technique increases the risk of developing an incisional hernia [38]. Various studies showed that most incisional hernias after MLC occurred in naval incisions with the most extensive fascial cut $[14,50,51]$. Several recent meta-analyses showed a higher hernia rate in the SLC group $[7,9,12]$. In the three mentioned meta-analyses, the high hernia rate may be traced back to a single RCT with a significant impact and a particularly high level of incisional hernia 
rate [38]. If this single study is excluded, the differences in incisional hernia rates are similar, according to Antoniou et al. [12]. Haueter and colleagues performed a subgroup analysis without this particular study of Marks et al. and no longer found a significant difference in incisional hernias [9]. Arezzo et al. discussed the high rate of incisional hernias in the respective study with particular attention to the high occurrence of superficial wound infections as a risk factor for incisional hernia occurrence [7]. Antoniou et al. noted that there was a lack of experience in the surgeons performing SLC in this particular RCT [12]. When considering only studies with three-port MLC, there was no difference in hernia rate compared to SLC [7]. The comparatively low overall rates of incisional hernia should be emphasized as $2.2 \%$ and $1.3 \%$ in the SLC group and $0.7 \%$ and $0.3 \%$ in the MLC group. These hernia rates are lower than those in the present trial. The reason for this difference may be the difference in follow-up length. The studies included in Antoniou et al. observed their patients for up to 1 year. Haueter et al. showed a maximum follow-up of 69 weeks, and the meta-analysis of Arezzo et al. did not mention the follow-up length. A follow-up of 2 3 years is recommended to elucidate the real risk for incisional hernia [14]. Very few studies fulfilled these recommendations, including a study of the Danish National Patient Registry with a mean follow-up of 48 months. Christoffersen et al. demonstrated similar hernia rates of $4 \%$ in the SLC group and $6 \%$ in the MLC group [14]. Julliard et al. analysed the occurrence and risk factors for incisional hernias and showed a hernia rate of $7.9 \%$ after a mean follow-up of 41 months [52]. Bury et al. examined the contradiction in occurrence of incisional hernia and compared the works of Antoniou et al. and Christoffersen et al. He recognized both studies as equivalent in their level of evidence and stated the need for long-term investigations of this topic [13]. We can make an essential contribution with our almost 6-year follow-up period. The present trial detected similar hernia rates. The hernia rate was $5.7 \%$ in the SLC group and $8.3 \%$ in the MLC group. Therefore, the hernia rate described by Christoffersen et al. is supported by our results with an even longer follow-up period of 70.4 months on average. There were several risk factors mentioned in the relevant literature, especially the duration of surgery, the intraoperative manipulation and the method of fascia closure [53, 54]. In many cases, the importance of fascia closure in connection with the longer incision and hernia occurrence was stressed [9, $19,32,52]$. Because only experienced surgeons participated in the present trial, a short duration of surgery, minimal intraoperative manipulation and a standardized facial closure are assumed. This result suggests that the incisional hernia rate does not differ between the surgical techniques using experienced surgeons and a standardized fascial closure.

There are some other possible operative alternatives to SLC regarding the minimization of the incision. Mini-laparoscopy using 3- to 5-mm trocars is a widespread alternative to standard MLC [24]. A metaanalysis comparing different kinds of laparoscopic cholecystectomy found four-port mini-laparoscopy favourable regarding the highest cosmetic score and the lowest postoperative morbidity, and SLC favourable regarding the lowest postoperative pain and shortest hospital stay [55]. Another alternative that can even be performed under local anaesthesia as day-care surgery is a small-incision cholecystectomy through a cylinder retractor. Grau-Talens et al. showed in a large prospective study that this operation is safe and feasible in three out of four patients with cholelithiasis [56].

The present study has some limitations. Neither the postoperative care surgeons nor the patients were blinded in our trial. Just recently, the Study Centre of the German Surgical Society formulated recommendations for the use of blinding in surgical trials that should be considered in future trials [57]. Another point of limitation is that we did not assess information on the exact extension of the umbilical incision to recover the gallbladder in the MLC group. In some cases, especially with large gallstones, it is necessary to widen the fascial incision to securely recover the gallbladder from the abdominal cavity. This need may even widen the fascial incision in MLC to the size of the incision made in SLC procedures. Another point of criticism is the high lost-to-follow-up rate in this study, which was probably due the long follow-up period. Furthermore, the patients were only subjected to a physical examination when they were interested in such an examination or reported discomfort. Therefore, a real hernia rate higher than that reported in the study may not have been found due to the lack of detection of asymptomatic hernias rather than their non-occurrence.

\section{Conclusion}

The present study demonstrates that SLC is a safe and feasible alternative to cholecystectomy in experienced surgical hands with short-term advantages in cosmetic results, postoperative pain and length of hospital stay, but the advantages regarding cosmesis and pain do not persist in the long term. Almost 6 years after surgery, no difference in pain and cosmetic scores and incisional hernia rates between SLC and MLC were noted.

Funding Information Open Access funding provided by Projekt DEAL.

\section{Compliance with ethical standards}

The authors declare that they have no conflicts of interest. All procedures performed in studies involving human participants were in accordance with the ethical standards of the institutional and national research committee and with the 1964 Helsinki declaration and its later amendments or 
comparable ethical standards. Informed consent was obtained from all individual participants included in the study.

Open Access This article is licensed under a Creative Commons Attribution 4.0 International License, which permits use, sharing, adaptation, distribution and reproduction in any medium or format, as long as you give appropriate credit to the original author(s) and the source, provide a link to the Creative Commons licence, and indicate if changes were made. The images or other third party material in this article are included in the article's Creative Commons licence, unless indicated otherwise in a credit line to the material. If material is not included in the article's Creative Commons licence and your intended use is not permitted by statutory regulation or exceeds the permitted use, you will need to obtain permission directly from the copyright holder. To view a copy of this licence, visit http://creativecommons.org/licenses/by/4.0/.

\section{References}

1. Reynolds W (2001) The first laparoscopic cholecystectomy. JSLS 5(1):89-94

2. Navarra G, Pozza E, Occhionorelli S, Carcoforo P, Donini I (1997) One-wound laparoscopic cholecystectomy. Br J Surg 84(5):695

3. Gaujoux S, Maggiori L, Bretagnol F, Ferron M, Panis Y (2012) Safety, feasibility, and short-term outcomes of single port access colorectal surgery: a single institutional case-matched study. J Gastrointest Surg 16(3):629-634. https://doi.org/10.1007/s11605011-1780-7

4. Gawart M, Dupitron S, Lutfi R (2012) Laparoendoscopic singlesite gastric bands versus standard multiport gastric bands: a comparison of technical learning curve measured by surgical time. Am J Surg 203(3):327-329; discussion 330. https://doi.org/10.1016/j. amjsurg.2011.10.001

5. Kuroki T, Adachi T, Okamoto T, Kanematsu T (2011) Singleincision laparoscopic distal pancreatectomy. Hepatogastroenterology 58(107-108):1022-1024

6. Raakow J, Liesaus H-G, Neuhaus P, Raakow R (2015) Singleincision versus multiport laparoscopic appendectomy: a casematched comparative analysis. Surg Endosc 29(6):1530-1536. https://doi.org/10.1007/s00464-014-3837-7

7. Arezzo A, Passera R, Forcignano E, Rapetti L, Cirocchi R, Morino M (2018) Single-incision laparoscopic cholecystectomy is responsible for increased adverse events: results of a meta-analysis of randomized controlled trials. Surg Endosc 32(9):3739-3753. https://doi.org/10.1007/s00464-018-6143-y

8. Bucher P, Pugin F, Buchs NC, Ostermann S, Morel P (2011) Randomized clinical trial of laparoendoscopic single-site versus conventional laparoscopic cholecystectomy. Br J Surg 98(12): 1695-1702. https://doi.org/10.1002/bjs.7689

9. Haueter R, Schutz T, Raptis DA, Clavien P-A, Zuber M (2017) Meta-analysis of single-port versus conventional laparoscopic cholecystectomy comparing body image and cosmesis. Br J Surg 104(9):1141-1159. https://doi.org/10.1002/bjs.10574

10. Tamini N, Rota M, Bolzonaro E, Nespoli L, Nespoli A, Valsecchi MG, Gianotti L (2014) Single-incision versus standard multipleincision laparoscopic cholecystectomy: a meta-analysis of experimental and observational studies. Surg Innov 21(5):528-545. https://doi.org/10.1177/1553350614521017

11. Antoniou SA, Antoniou GA, Granderath F-A (2016) Comparing systematic reviews and meta-analyses of randomized clinical trials with cohort studies: a paradigm of single-incision laparoscopic surgery. Hernia 20(1):13-14. https://doi.org/10.1007/s10029-015$1430-1$
12. Antoniou SA, Morales-Conde S, Antoniou GA, Granderath FA, Berrevoet F, Muysoms FE (2016) Single-incision laparoscopic surgery through the umbilicus is associated with a higher incidence of trocar-site hernia than conventional laparoscopy: a meta-analysis of randomized controlled trials. Hernia 20(1):1-10. https://doi.org/10. 1007/s10029-015-1371-8

13. Bury K, Pawlak M, Smietanski M, Muysoms F (2016) Singleincision port-site herniation: meta-analysis vs. nationwide cohort study. Hernia 20(1):11-12. https://doi.org/10.1007/s10029-0151401-6

14. Christoffersen MW, Brandt E, Oehlenschlager J, Rosenberg J, Helgstrand F, Jorgensen LN, Bardram L, Bisgaard T (2015) No difference in incidence of port-site hernia and chronic pain after single-incision laparoscopic cholecystectomy versus conventional laparoscopic cholecystectomy: a nationwide prospective, matched cohort study. Surg Endosc 29(11):3239-3245. https://doi.org/10. 1007/s00464-015-4066-4

15. Dindo D, Demartines N, Clavien P-A (2004) Classification of surgical complications: a new proposal with evaluation in a cohort of 6336 patients and results of a survey. Ann Surg 240(2):205-213

16. Baucom RB, Ousley J, Feurer ID, Beveridge GB, Pierce RA, Holzman MD, Sharp KW, Poulose BK (2016) Patient reported outcomes after incisional hernia repair-establishing the ventral hernia recurrence inventory. Am J Surg 212(1):81-88. https://doi.org/ 10.1016/j.amjsurg.2015.06.007

17. Arezzo A, Passera R, Bullano A, Mintz Y, Kedar A, Boni L, Cassinotti E, Rosati R, Fumagalli Romario U, Sorrentino M, Brizzolari M, Di Lorenzo N, Gaspari AL, Andreone D, Ed S, Navarra G, Lazzara S, Degiuli M, Shishin K, Khatkov I, Kazakov I, Schrittwieser R, Carus T, Corradi A, Sitzman G, Lacy A, Uranues S, Szold A, Morino M (2017) Multi-port versus single-port cholecystectomy: results of a multi-centre, randomised controlled trial (MUSIC trial). Surg Endosc 31(7):2872-2880. https://doi.org/10. 1007/s00464-016-5298-7

18. Lurje G, Raptis DA, Steinemann DC, Amygdalos I, Kambakamba P, Petrowsky H, Lesurtel M, Zehnder A, Wyss R, Clavien P-A, Breitenstein S (2015) Cosmesis and body image in patients undergoing single-port versus conventional laparoscopic cholecystectomy: a multicenter double-blinded randomized controlled trial (SPOCC-trial). Ann Surg 262(5):728-734; discussion 734-725. https://doi.org/10.1097/sla.0000000000001474

19. Omar MA, Redwan AA, Mahmoud AG (2017) Single-incision versus 3-port laparoscopic cholecystectomy in symptomatic gallstones: a prospective randomized study. Surgery 162(1):96-103. https://doi.org/10.1016/j.surg.2017.01.006

20. Pan M-X, Jiang Z-S, Cheng Y, Xu X-P, Zhang Z, Qin J-S, He G-L, Xu T-C, Zhou C-J, Liu H-Y, Gao Y (2013) Single-incision vs threeport laparoscopic cholecystectomy: prospective randomized study. World J Gastroenterol 19(3):394-398. https://doi.org/10.3748/wjg. v19.i3.394

21. Ito E, Takai A, Imai Y, Otani H, Onishi Y, Yamamoto Y, Ogawa K, Tohyama T, Fukuhara S, Takada Y (2019) Quality of life after single-incision laparoscopic cholecystectomy: a randomized, clinical trial. Surgery 165(2):353-359. https://doi.org/10.1016/j.surg. 2018.08.004

22. Lai ECH, Yang GPC, Tang CN, Yih PCL, Chan OCY, Li MKW (2011) Prospective randomized comparative study of single incision laparoscopic cholecystectomy versus conventional four-port laparoscopic cholecystectomy. Am J Surg 202(3):254-258. https://doi.org/10.1016/j.amjsurg.2010.12.009

23. Deveci U, Barbaros U, Kapakli MS, Manukyan MN, Simsek S, Kebudi A, Mercan S (2013) The comparison of single incision laparoscopic cholecystectomy and three port laparoscopic cholecystectomy: prospective randomized study. J Korean Surg Soc 85(6):275-282. https://doi.org/10.4174/jkss.2013.85.6.275 
24. Saad S, Strassel V, Sauerland S (2013) Randomized clinical trial of single-port, minilaparoscopic and conventional laparoscopic cholecystectomy. Br J Surg 100(3):339-349. https://doi.org/10.1002/bjs. 9003

25. Wagner MJ, Kern H, Hapfelmeier A, Mehler J, Schoenberg MH (2013) Single-port cholecystectomy versus multi-port cholecystectomy: a prospective cohort study with 222 patients. World J Surg 37(5):991-998. https://doi.org/10.1007/s00268-013-1946-4

26. Evers L, Bouvy N, Branje D, Peeters A (2017) Single-incision laparoscopic cholecystectomy versus conventional four-port laparoscopic cholecystectomy: a systematic review and meta-analysis. Surg Endosc 31:3437-3448. https://doi.org/10.1007/s00464-0165381-0

27. Solomon D, Bell RL, Duffy AJ, Roberts KE (2010) Single-port cholecystectomy: small scar, short learning curve. Surg Endosc 24(12):2954-2957. https://doi.org/10.1007/s00464-010-1070-6

28. Peters JH, Ellison EC, Innes JT, Liss JL, Nichols KE, Lomano JM, Roby SR, Front ME, Carey LC (1991) Safety and efficacy of laparoscopic cholecystectomy. A prospective analysis of 100 initial patients. Ann Surg 213(1):3-12

29. Zucker KA, Bailey RW, Gadacz TR, Imbembo AL (1991) Laparoscopic guided cholecystectomy. Am J Surg 161(1):36-42 discussion 42-34

30. Lirici MM, Califano AD, Angelini P, Corcione F (2011) Laparoendoscopic single site cholecystectomy versus standard laparoscopic cholecystectomy: results of a pilot randomized trial. Am J Surg 202(1):45-52. https://doi.org/10.1016/j.amjsurg.2010.06.019

31. Abdelrahman AM, Bingener J, Yu D, Lowndes BR, Mohamed A, McConico AL, Hallbeck MS (2016) Impact of single-incision laparoscopic cholecystectomy (SILC) versus conventional laparoscopic cholecystectomy (CLC) procedures on surgeon stress and workload: a randomized controlled trial. Surg Endosc 30(3):1205-1211. https://doi.org/10.1007/s00464-015-4332-5

32. Li T, Kim G, Chang S (2016) Tips and tricks to avoid bile duct injury in SILC: an experience of 500 cases. Surg Endosc 30(11): 4750-4755. https://doi.org/10.1007/s00464-016-4802-4

33. Rimonda R, Tang B, Brown SI, Cuschieri A (2012) Comparison of endoscopic task performance with crossed versus uncrossed straight and curved instruments through a single port. Surg Endosc 26(12):3605-3611. https://doi.org/10.1007/s00464-0122379-0

34. Connor S, Garden OJ (2006) Bile duct injury in the era of laparoscopic cholecystectomy. Br J Surg 93(2):158-168. https://doi.org/ $10.1002 /$ bjs.5266

35. Nuzzo G, Giuliante F, Giovannini I, Ardito F, D'Acapito F, Vellone M, Murazio M, Capelli G (2005) Bile duct injury during laparoscopic cholecystectomy: results of an Italian national survey on 56 591 cholecystectomies. Arch Surg 140(10):986-992. https://doi. org/10.1001/archsurg.140.10.986

36. Allemann P, Demartines N, Schafer M (2014) Remains of the day: biliary complications related to single-port laparoscopic cholecystectomy. World J Gastroenterol 20:843-851. https://doi.org/10. 3748/wjg.v20.i3.843

37. Joseph M, Phillips MR, Farrell TM, Rupp CC (2012) Single incision laparoscopic cholecystectomy is associated with a higher bile duct injury rate: a review and a word of caution. Ann Surg 256(1): 1-6. https://doi.org/10.1097/SLA.0b013e3182583fde

38. Marks JM, Phillips MS, Tacchino R, Roberts K, Onders R, DeNoto G, Gecelter G, Rubach E, Rivas H, Islam A, Soper N, Paraskeva P, Rosemurgy A, Ross S, Shah S (2013) Single-incision laparoscopic cholecystectomy is associated with improved cosmesis scoring at the cost of significantly higher hernia rates: 1 -year results of a prospective randomized, multicenter, single-blinded trial of traditional multiport laparoscopic cholecystectomy vs single-incision laparoscopic cholecystectomy. J Am Coll Surg 216(6):1037-1047; discussion 1047-1038. https://doi.org/10.1016/j.jamcollsurg.2013.02. 024

39. Hao XY, Shen YF, Wei YG, Liu F, Li HY, Li B (2017) Safety and effectiveness of day-surgery laparoscopic cholecystectomy is still uncertain: meta-analysis of eight randomized controlled trials based on GRADE approach. Surg Endosc 31(12):4950-4963. https://doi. org/10.1007/s00464-017-5610-1

40. Vaughan J, Gurusamy KS, Davidson BR (2013) Day-surgery versus overnight stay surgery for laparoscopic cholecystectomy. Cochrane Database Syst Rev 7:CD006798. https://doi.org/10. 1002/14651858.CD006798.pub4

41. Agresta F, Campanile FC, Vettoretto N, Silecchia G, Bergamini C, Maida P, Lombari P, Narilli P, Marchi D, Carrara A, Esposito MG, Fiume S, Miranda G, Barlera S, Davoli M, Italian Surgical Societies Working G (2015) Laparoscopic cholecystectomy: consensus conference-based guidelines. Langenbeck's Arch Surg 400(4): 429-453. https://doi.org/10.1007/s00423-015-1300-4

42. Overby DW, Apelgren KN, Richardson W, Fanelli R, Society of American G, Endoscopic S (2010) SAGES guidelines for the clinical application of laparoscopic biliary tract surgery. Surg Endosc 24(10):2368-2386. https://doi.org/10.1007/s00464-010-1268-7

43. Tsimoyiannis EC, Tsimogiannis KE, Pappas-Gogos G, Farantos C, Benetatos N, Mavridou P, Manataki A (2010) Different pain scores in single transumbilical incision laparoscopic cholecystectomy versus classic laparoscopic cholecystectomy: a randomized controlled trial. Surg Endosc 24(8):1842-1848. https://doi.org/10.1007/ s00464-010-0887-3

44. Bencsath KP, Falk G, Morris-Stiff G, Kroh M, Walsh RM, Chalikonda S (2012) Single-incision laparoscopic cholecystectomy: do patients care? J Gastrointest Surg 16(3):535-539. https:// doi.org/10.1007/s11605-011-1785-2

45. Jung GO, Park DE, Chae KM (2012) Clinical results between single incision laparoscopic cholecystectomy and conventional 3-port laparoscopic cholecystectomy: prospective case-matched analysis in single institution. J Korean Surg Soc 83(6):374-380. https:// doi.org/10.4174/jkss.2012.83.6.374

46. Chekan E, Moore M, Hunter TD, Gunnarsson C (2013) Costs and clinical outcomes of conventional single port and microlaparoscopic cholecystectomy. JSLS 17(1):30-45. https://doi.org/ $10.4293 / 108680812$ X13517013317635

47. Newman RM, Umer A, Bozzuto BJ, Dilungo JL, Ellner S (2016) Surgical value of elective minimally invasive gallbladder removal: a cost analysis of traditional 4-port vs single-incision and robotically assisted cholecystectomy. J Am Coll Surg 222(3):303-308. https://doi.org/10.1016/j.jamcollsurg.2015.12.016

48. Saidy MN, Patel SS, Choi MW, Al-Temimi M, Tessier DJ (2015) Single incision laparoscopic cholecystectomy performed via the "marionette" technique shows equivalence in outcome and cost to standard four port laparoscopic cholecystectomy in a selected patient population. Am Surg 81(10):1015-1020

49. Shussman N, Kedar A, Elazary R, Abu Gazala M, Rivkind AI, Mintz Y (2014) Reusable single-port access device shortens operative time and reduces operative costs. Surg Endosc 28(6):19021907. https://doi.org/10.1007/s00464-013-3411-8

50. Bunting DM (2010) Port-site hernia following laparoscopic cholecystectomy. JSLS 14(4):490-497. https://doi.org/10.4293/ $108680810 \times 12924466007728$

51. Erdas E, Dazzi C, Secchi F, Aresu S, Pitzalis A, Barbarossa M, Garau A, Murgia A, Contu P, Licheri S, Pomata M, Farina G (2012) Incidence and risk factors for trocar site hernia following 
laparoscopic cholecystectomy: a long-term follow-up study. Hernia 16(4):431-437. https://doi.org/10.1007/s10029-012-0929-y

52. Julliard O, Hauters P, Possoz J, Malvaux P, Landenne J, Gherardi D (2016) Incisional hernia after single-incision laparoscopic cholecystectomy: incidence and predictive factors. Surg Endosc 30(10): 4539-4543. https://doi.org/10.1007/s00464-016-4790-4

53. Comajuncosas J, Hermoso J, Gris P, Jimeno J, Orbeal R, Vallverdú H, López Negre JL, Urgellés J, Estalella L, Parés D (2014) Risk factors for umbilical trocar site incisional hernia in laparoscopic cholecystectomy: a prospective 3-year follow-up study. Am J Surg 207(1):1-6. https://doi.org/10.1016/j.amjsurg.2013.05.010

54. Jayaraman S, Rao SD (2013) Case series of umbilical and extraumbilical port site herniae. Indian J Surg 75(Suppl 1):488-491. https://doi.org/10.1007/s12262-013-0881-9

55. Li L, Tian J, Tian H, Sun R, Wang Q, Yang K (2014) The efficacy and safety of different kinds of laparoscopic cholecystectomy: a network meta analysis of 43 randomized controlled trials. PLoS One 9(2):e90313. https://doi.org/10.1371/journal.pone.0090313

56. Grau-Talens EJ, Motos-Mico JJ, Giraldo-Rubio R, AparicioGallego JM, Salgado JF, Ibanez CD, Mangione-Castro PG, Arribas-Jurado M, Jordan-Chaves C, Arias-Diaz J (2018) Smallincision cholecystectomy (through a cylinder retractor) under local anaesthesia and sedation: a prospective observational study of five hundred consecutive cases. Langenbeck's Arch Surg 403(6):733740. https://doi.org/10.1007/s00423-018-1707-9

57. Probst P, Zaschke S, Heger P, Harnoss JC, Huttner FJ, Mihaljevic AL, Knebel P, Diener MK (2019) Evidence-based recommendations for blinding in surgical trials. Langenbeck's Arch Surg 404(3): 273-284. https://doi.org/10.1007/s00423-019-01761-6

Publisher's note Springer Nature remains neutral with regard to jurisdictional claims in published maps and institutional affiliations. 